Ensino, Saúde e Ambiente - V9 (2), pp. 12-26, Ago. 2016.

\title{
PESQUISA-AÇÃO SOBRE ENSINO-APRENDIZAGEM DE MICROBIOLOGIA NO ENSINO MÉDIO
}

\section{ACTION RESEARCH ON MICROBIOLOGY TEACHING AND LEARNING IN HIGH SCHOOL}

\author{
Luiz Sodré Neto ${ }^{1}$, Jhousymere Almeida Diniz ${ }^{2}$ \\ ${ }^{1}$ Universidade Federal de Campina Grande/ Centro de Educação e Saúde/ Laboratório de Ensino de \\ Microbiologia, luizsodre@ufcg.edu.br \\ ${ }^{2}$ Universidade Federal de Campina Grande/ Curso de Licenciatura em Ciências Biológicas, \\ jhousymere@gmail.com
}

\section{RESUMO}

O papel do professor do Ensino Básico perpassa o cumprimento de programas de disciplinas específicas, chegando à análise do que os estudantes já conhecem, para que sejam desenvolvidas e/ou adaptadas estratégias de trabalho planejadas. Além do que os estudantes sabem, é importante entender como eles aprendem e, a partir disto, estabelecer uma conduta em sala de aula considerando principalmente às possíveis relações entre os conteúdos e a realidade deles. O presente trabalho objetivou analisar a aprendizagem de aspectos fundamentais da microbiologia no Ensino Médio, bem como usar e sugerir o uso de estratégias de ensino que valorizem a divulgação científica. Para isto, foi aplicado um questionário do qual a análise dos resultados subsidiou o planejamento e a execução de uma intervenção na escola-alvo na intenção de apresentar aspectos da microbiologia aplicada e do ensino do tema. Considerou-se, portanto, que parece haver lacunas no ensino que podem ser identificadas, se a sala de aula funcionar também como um campo de pesquisa para o professor, e que propostas de contextualização podem auxiliar no processo de ensino-aprendizagem.

Palavras-chaves: Autoavaliação; ensino-aprendizagem; ensino de biologia.

\begin{abstract}
The role of basic education teacher goes beyond the accomplishment of specific disciplines programs, to the analysis of what the students already know, so that the planned strategies are developed and /or adapted. In addition to the students know, it is important to understand how they learn and, from that, establish the conduct in the classroom, especially considering possible relationships between the contents and their reality. This work aimed to analyze learning about fundamental aspects of Microbiology in high school, as well as use and suggest use of teaching strategies to enhance scientific divulgation. For this, there was a questionnaire which it analysis supported the planning and execution of an intervention in the target school intending to present aspects of applied microbiology and of the teaching. Therefore it was considered there appear to be gaps in teaching that can be identified if the classroom work as well as a search field to the teacher, and contextualization proposals can assist in teaching and learning process..
\end{abstract}

Key words: Auto-evaluation; teaching-learning; biology teaching. 
Ensino, Saúde e Ambiente - V9 (2), pp. 12-26, Ago. 2016.

\section{INTRODUÇÃO}

A tecnologia e os meios de comunicação fazem com que a sociedade seja amplamente conectada e tenha cada vez mais facilidade de acesso à informação. Na escola, os estudantes chegam com informações também provenientes da mídia e geralmente separam os conhecimentos cotidianos do que é trabalhado pelos professores em sala de aula. Parece haver uma lacuna entre o que deve ser ensinado e o que deve servir para a formação dos estudantes, configurando um desafio que reflete na prática docente e no comportamento discente.

Para conseguir trabalhar, de maneira que seja favorecida cada vez mais a aprendizagem dos estudantes, o professor precisa ter uma desenvoltura que seja atrativa independentemente do uso de ferramentas tecnológicas. Ensinar, portanto, tem sido para os professores um desafio a ser superado, tendo em vista que muitos deles relatam que as metodologias tradicionais já não servem e devem ser adaptadas ou superadas.

$\mathrm{Na}$ Biologia existem particularidades quanto ao entendimento de alguns temas que exigem mais abstração e por isso apresentam um maior grau de dificuldade. Para o ensino desses temas, os professores normalmente tentam empregar alternativas que ajudem os alunos no entendimento dos conceitos e relações e, consequentemente, na transformação da ideia de que a biologia é constituída de termos complicados de assimilar e compreender. Tais alternativas muitas vezes se resumem às aulas práticas, embora seja frequentemente evidenciada a acessibilidade aos materiais de laboratório, como comentam Barbosa e Barbosa (2010), que tem diminuindo à custa de seus elevados preços e favorecido a procura por outras estratégias que supram a necessidade de aprofundar conteúdos com o dinamismo de aulas práticas.

O Ensino de Biologia depende do empenho e do planejamento do professor além do mero cumprimento de um cronograma dos conteúdos a serem ministrados. Nesse aspecto, uma abordagem que valorize a qualidade do ensino sem depender da quantidade de informações, pode ser uma maneira de se chegar a uma forma de ensinar que garanta uma aprendizagem de qualidade.

Como alternativas ao modelo tipicamente expositivo encontrado em grande parte das escolas, tomando como base a alfabetização científica e a aprendizagem 
Ensino, Saúde e Ambiente - V9 (2), pp. 12-26, Ago. 2016.

significativa, Silva e Bastos (2012) discutem que, dentro dos currículos de Ciências e Biologia no Ensino Básico, a microbiologia necessita de novas propostas para o desenvolvimento dos conteúdos ministrados em sala de aula. O estudo do tema precisa ser contextualizado, pois, em concordância com a descrição Cândido et al. (2015), ele serve como suporte para tornar indivíduos mais conscientes com relação a aspectos inseridos no dia-dia.

Com base nesses princípios, sugerem-se reflexões norteadas por questionamentos como: $\mathrm{O}$ que é preciso mudar para que seja melhorado o ensinoaprendizagem de Biologia?; A escola está preparada para mudanças em termos de estrutura física e recursos humanos?; Os professores têm uma formação adequada e estão dispostos para desaprender e reaprender?

Entender como os alunos aprendem pode ajudar a preparar as aulas, além de evidenciar as falhas ou lacunas dos métodos usados. Não existe uma fórmula ou receita pronta para uso em sala de aula, porém é sugerido que o professor se atualize com frequência e reveja a sua didática e a sua atitude para que haja um planejamento adequado. Nessa perspectiva, é possível pensar um ensino de microbiologia que busque simplificar os conceitos a fim de proporcionar um entendimento mais elaborado e associado ao cotidiano.

Muitas das aulas ministradas são meras representações do livro didático na lousa (OVIGLI, 2010). Nesse caso, seria necessária uma abordagem mais dinâmica do conteúdo, na qual fosse valorizado o nível de entendimento pré-existente do aluno e a partir disto, fosse estimulada a busca por novas informações, associada ao desenvolvimento de habilidades e de aprendizagem crítica.

Uma estratégia de investigação que pode estabelecer uma ligação entre a detecção de possíveis problemas na aprendizagem e a proposta de alternativas de ensino participativas é a pesquisa-ação que, segundo Thiollent e Colette (2014), tem como objetivo usar-se da realidade e da situação para propor uma metodologia que se adapte às situações por meio do levantamento de dados que mostrem a realidade da aprendizagem. Por tais características, Tripp (2005) considera a pesquisa-ação como um tipo de investigação-ação que tem o planejamento condicionado pelos objetivos e circunstâncias de cada público em cada situação. 
Ensino, Saúde e Ambiente - V9 (2), pp. 12-26, Ago. 2016.

Procurar saber como os alunos entendem determinado conteúdo seria uma boa forma de programar e explorar assuntos que sejam significativos em sua aprendizagem dando ao professor um ótimo ponto de partida para a preparação de suas aulas. Engel (2000) destaca a sala de aula como laboratório de pesquisa do professor, tornando a pesquisa-ação um instrumento de grande valia para a análise do andamento do processo de ensino-aprendizagem em qualquer que seja o nível de ensino ou a área de conhecimento.

A pesquisa-ação permite a análise de um problema ou de uma situação, dando oportunidade para que o professor possa agir diretamente na causa, além de fazer avaliação de seus próprios métodos (THIOLLENT e COLETTE ,2014; ENGEL, 2000). Ela pode ser, portanto, uma ferramenta de grande utilidade quando se trata de repensar os métodos e analisar a eficácia dos mesmos, auxiliando o professor em sua autoavaliação e na consequente reflexão sobre a forma de lidar com as suas turmas e as respectivas particularidades.

No contexto da atuação do professor de Biologia, o presente trabalho buscou analisar como está acontecendo aprendizagem, especificamente de aspectos fundamentais da microbiologia, por parte de discentes do Ensino Médio, bem como usar e sugerir o uso de estratégias de ensino que valorizem a divulgação científica dos conteúdos em seus aspectos científicos, sociais e econômicos.

\section{METODOLOGIA}

Como parte do desenvolvimento da pesquisa-ação, a primeira etapa do trabalho foi a confecção do instrumento de coleta dos dados composto por questões referentes aos aspectos básicos da microbiologia em termos de conceitos e aplicabilidades. O questionário (Documento Suplementar) foi elaborado tendo como critério a busca pelo entendimento de aspectos de contextualização da microbiologia básica, bem como as percepções apresentadas pelos estudantes sobre os conteúdos trabalhados em sala de aula.

O questionário foi composto por sete questões, sendo quatro de múltipla escolha e três dissertativas. A análise e exposição das respostas destas três últimas foram feitas por meio da categorização de acordo com as ideias centrais identificadas no 
Ensino, Saúde e Ambiente - V9 (2), pp. 12-26, Ago. 2016.

texto escrito pelos participantes. Depois de organizados e quantificados, todos os dados foram apresentados em forma de gráficos.

As questões foram respondidas por 54 estudantes, entre 16 e 18 anos de idade, regularmente matriculados nas 02 turmas de $3^{\circ}$ série do Ensino Médio de uma Escola Estadual localizada na cidade de Nova Floresta-PB, onde foram feitos levantamentos de dados correspondentes ao conhecimento prévios dos alunos.

Com base nos resultados, discutiram-se os possíveis problemas existentes na aprendizagem de assuntos da microbiologia básica. Por fim, após análise e discussão dos dados obtidos, foi planejada uma estratégia de ação para que a tentativa de melhorar as abordagens dos temas quanto à sua aplicabilidade e contextualização fosse direcionada a partir do conhecimento dos possíveis entraves à aprendizagem na escolaalvo.

Buscou-se também, por meio do uso da presente pesquisa-ação, estimular os leitores deste trabalho a usarem este tipo de prática desde a sua formação docente até o seu planejamento de aulas, independentemente do nível de ensino envolvido.

\section{RESULTADOS E DISCUSSÃO}

Os dados obtidos na presente pesquisa permitiram identificar alguns problemas conceituais provavelmente provenientes da sequência da prática de ensino tradicional durante todo o Ensino Básico. Não obstante, aparecem resultados contraditórios que são possivelmente fruto do descompromisso de alguns estudantes no momento de responder as questões.

Os dados obtidos nas questões de números de 1 a 7 estão apresentados, nesta ordem, nos gráficos respectivamente enumerados. A figura 1 representa o número de estudantes que afirmaram ou negaram o uso conceitos da biologia no seu cotidiano.

Figura 1: Número de respostas "sim" e "não" sobre o uso da biologia no cotidiano. 
Ensino, Saúde e Ambiente - V9 (2), pp. 12-26, Ago. 2016.

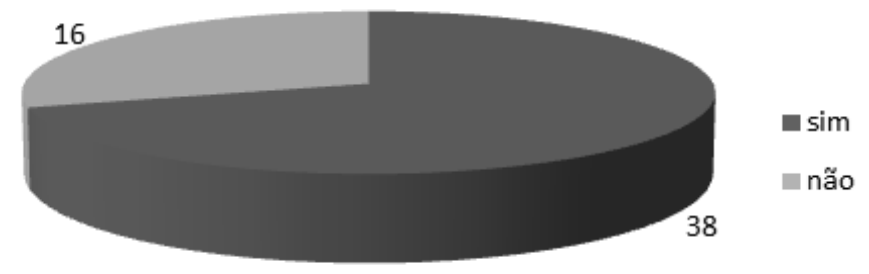

Fonte: autoria própria

Esta primeira questão teve como objetivo compreender diretamente se os alunos têm noção de que a biologia está presente na vida das pessoas. Nesse caso, 38 dos 54 estudantes marcaram a resposta "sim", enquanto os outros 16 marcaram "não". Percebe-se que a maioria dos alunos demonstra entender uma relação básica entre o que é estudado e o que é vivido diariamente. O fato preocupante é que, mesmo no último ano do ensino básico, ainda apareceram respostas negativas, evidenciando o desinteresse ou a incapacidade de contextualizar o que é visto na escola.

Albuquerque, Braga e Gomes (2012) citam que a forma de contextualização usada pelo professor e a forma de compreensão dos estudantes pode evitar que haja apenas memorização de termos que para eles não possuem fundamentos. Esses autores destacam ainda que a relação entre cotidiano e sala de aula deve ser feita pelo professor para que os estudantes despertem e compreendam que o estudo faz parte de sua realidade.

$\mathrm{Na}$ segunda questão (figura 2) foi abordada a relação estrita entre microrganismos e doenças, ou seja, uma ideia ainda frequentemente evidenciada entre estudantes do Ensino Básico. Essa concepção, identificada em 14 participantes, pode estar relacionada à tamanha disseminação de notícias e dados sobre doenças infecciosas, também no material didático de Ciências e Biologia. Antunes, Pileggi e Pazda (2012) também destacam a relação dos microrganismos direta e unicamente com doenças.

Figura 2: Número de respostas "sim" e "não" quanto à relação estrita entre microrganismos e doenças. 
Ensino, Saúde e Ambiente - V9 (2), pp. 12-26, Ago. 2016.

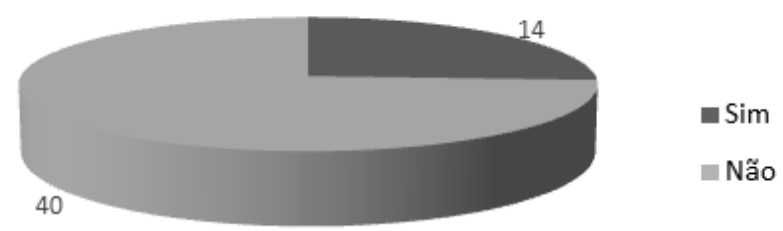

Fonte: autoria própria

Dos 54 sujeitos da pesquisa, 40 assinalaram a resposta "não". Isso pode ser um ponto favorável no que se diz respeito à aprendizagem da microbiologia e à concepção dos discentes em relação a outras funções dos seres microscópicos na natureza.

Ao serem questionados sobre a existência de microrganismos que trazem benefícios aos seres humanos (figura 3), na terceira questão, 49 estudantes apontaram um entendimento adequado, embora 05 deles ainda tenham permanecido com a ideia observada nas questões anteriores.

Figura 3: Número de respostas "sim" e "não" quanto à existência microrganismos que fazem bem ao ser humano.

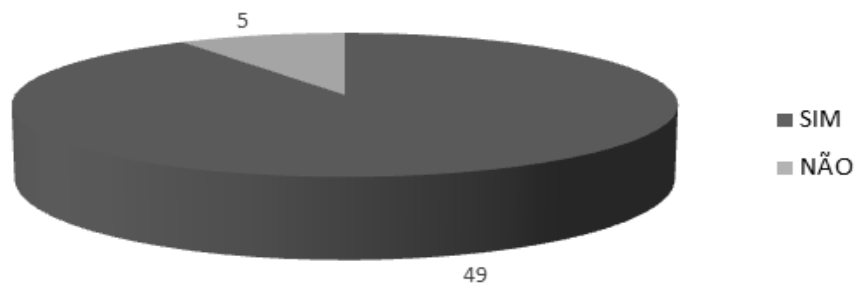

Fonte: autoria própria

Sabe-se que muitos seres microscópicos são usados na indústria para a produção de bens de consumo como alimentos, medicamentos, além daqueles que têm importantes papeis ecológicos e dos que são usados na biotecnologia. Apesar disso, comumente são identificados estudantes com dificuldades em relacionar os conteúdos trabalhados na escola com o a vida diária das pessoas. Esses estudantes podem fazer parte dos que não tem disposição para aprender ou não são estimulados de forma que consigam compreender a contextualização. 
Ensino, Saúde e Ambiente - V9 (2), pp. 12-26, Ago. 2016.

Na quarta questão, com respostas representadas nas cinco colunas da figura 4, os alunos poderiam marcar mais de uma opção para respostas corretas em relação ao habitat dos microrganismos. A alternativa mais marcada (45 alunos) foi a dos alimentos. A presença de microrganismos no ar, na água e na sujeira também foi considerada por 41 estudantes.

Figura 4: Número de respostas obtidas para as alternativas com os possíveis habitats dos microrganismos.

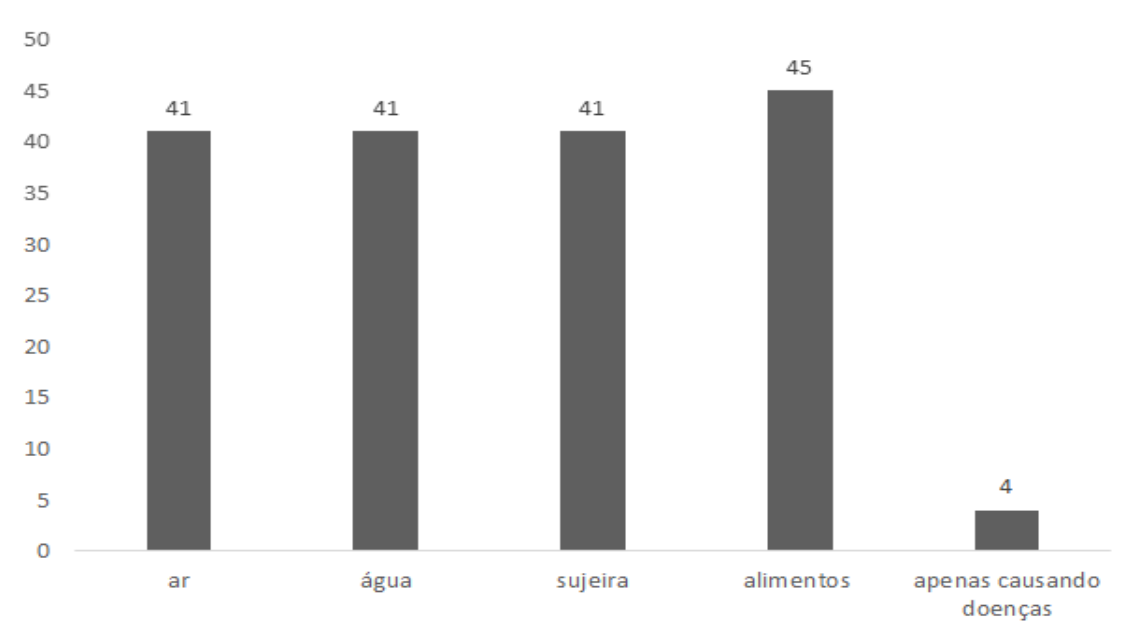

Fonte: autoria própria

Pelos dados obtidos foi possível perceber neste caso que a maioria dos estudantes conseguiu associar a presença de micróbios aos diversos ambientes propostos nas alternativas. Mas, apesar de os alunos apresentarem uma noção das relações adequadas no contexto microbiologia-cotidiano, ainda foram detectadas algumas incoerências que podem ter origens diversas, inclusive de falta de atenção na hora da leitura das questões.

Na sequência, as respostas das questões abertas estão apresentadas em colunas que representam as ideias centrais (categorias) nos gráficos. A figura 5 representa os resultados para cada categoria sugerida pelos autores de acordo com a dissertação dos estudantes em resposta a quinta questão.

Figura 5: Número de respostas e categorias representadas pelas ideias centrais sobre a contribuição dos microrganismos para a vida humana. 
Ensino, Saúde e Ambiente - V9 (2), pp. 12-26, Ago. 2016.

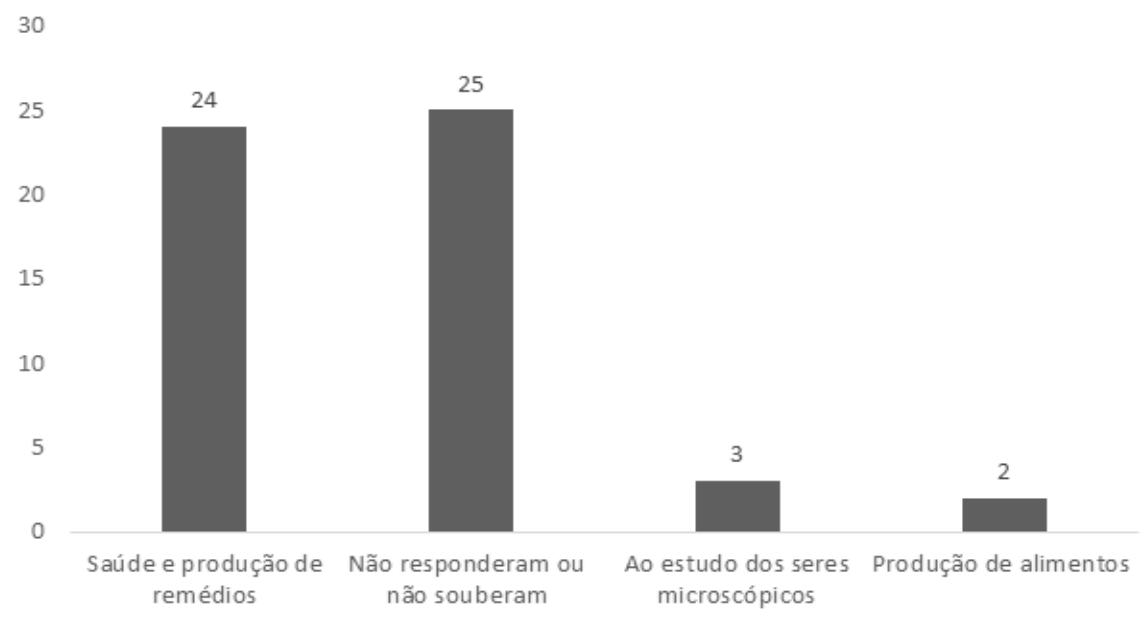

Fonte: autoria própria

Foram observadas algumas contradições nas respostas dissertativas quando comparadas às questões de múltipla escolha. As dúvidas podem estar associadas também ao modo como as aulas são trabalhadas, além do fato de a microbiologia ter o status de ser de difícil entendimento. Albuquerque, Braga e Gomes (2012), por exemplo, consideram a microbiologia como uma das áreas da biologia que apresentam dificuldades por parte dos estudantes para de associação com o seu cotidiano. Nesse caso, cabe ao professor fazer o papel de mediador das associações para que o conhecimento da sala de aula seja contextualizado no ambiente do aluno (KRASILCHIK; MANDINO, 2007). Para isto, o professor, desde a sua formação, deve ser estimulado a articular ensino e pesquisa (SPELTA et al., 2012) para que tenha a pesquisa-ação intrínseca à sua prática docente.

Na questão 6 (gráfico 6), a metade dos alunos participantes não respondeu ou não soube responder sobre a relação entre bactérias e alguns alimentos produzidos ou beneficiados por elas.

Figura 6: Número de respostas para as categorias evidenciadas na questão sobre as relações entre bactérias e alguns alimentos. 
Ensino, Saúde e Ambiente - V9 (2), pp. 12-26, Ago. 2016.

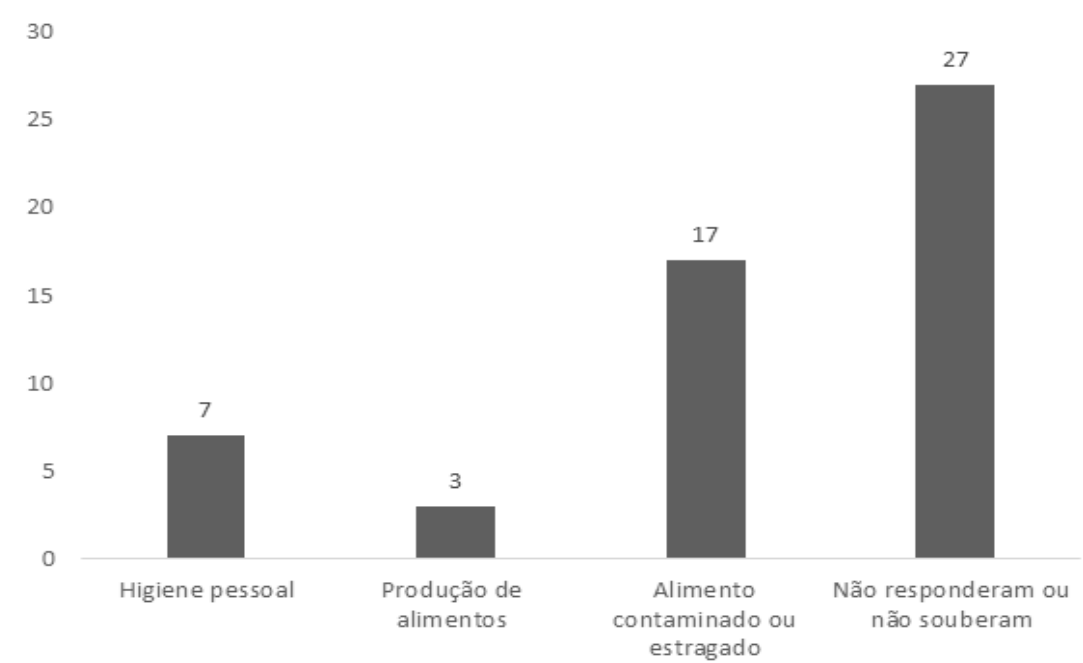

Fonte: autoria própria

Foi observado também no artigo de Azevedo e Sodré Neto (2014) que muitos alunos não conseguiam sintetizar uma resposta ou deixava em branco. Esta recorrência pode ser devido a alguns fatores já citados, como a falta de interesse, bem como à falta de incentivo à curiosidade e ao desenvolvimento de textos ou respostas escritas por eles mesmos.

Dos 27 estudantes que responderam a questão, 17 associaram bactérias aos alimentos contaminados ou estragados, enquanto 03 demonstraram ter a noção da produção de alimentos por parte delas. A partir desta análise é possível inferir que a concepção dos estudantes sobre os microrganismos ainda permanece aparentemente como resultado do que escutam fora da escola, também influenciados pela mídia, além do reflexo do ensino tradicional que limita a busca por informações e tende a separar ciência e vida cotidiana das pessoas.

Jacobucci e Jacobucci (2009, p.1) afirmam que:

“A Microbiologia que habita o imaginário das pessoas está relacionada às doenças devido à grande mídia televisiva e escrita no Brasil, que prioriza a divulgação de informações acerca dos microrganismos patogênicos, induzindo o telespectador/leitor leigo a imaginar que todos os fungos e bactérias são prejudiciais aos seres humanos."

Tentando entender como esses alunos interagem com imagens e texto, foi proposta uma questão em que eles interpretariam um quadrinho relacionado à vacina (figura 7). As respostas para a questão estão representadas na figura 8. 
Ensino, Saúde e Ambiente - V9 (2), pp. 12-26, Ago. 2016.

Figura 7: Quadrinhos ilustrativos

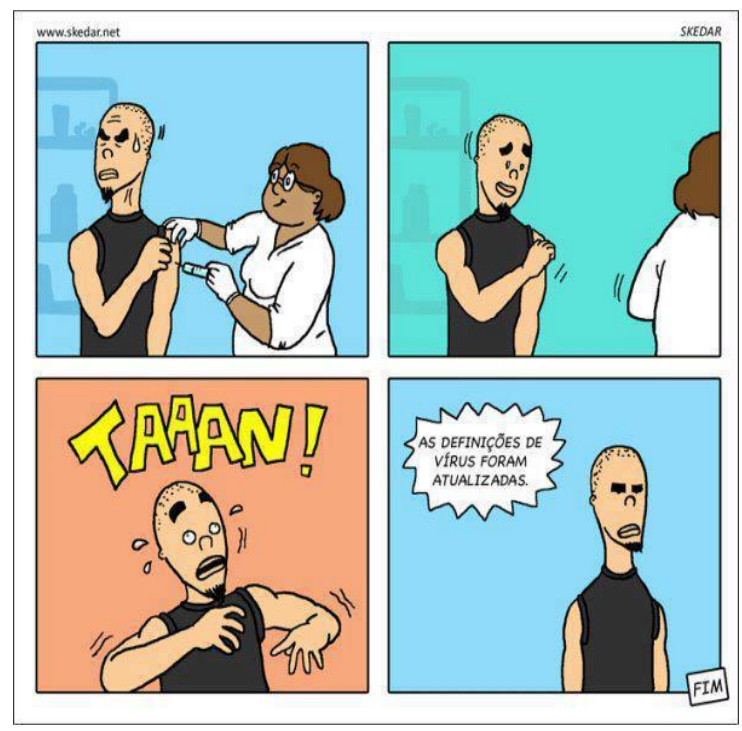

Fonte: www.skedar.net

Figura 8: Número de respostas para as categorias relacionadas à interpretação da figura 7

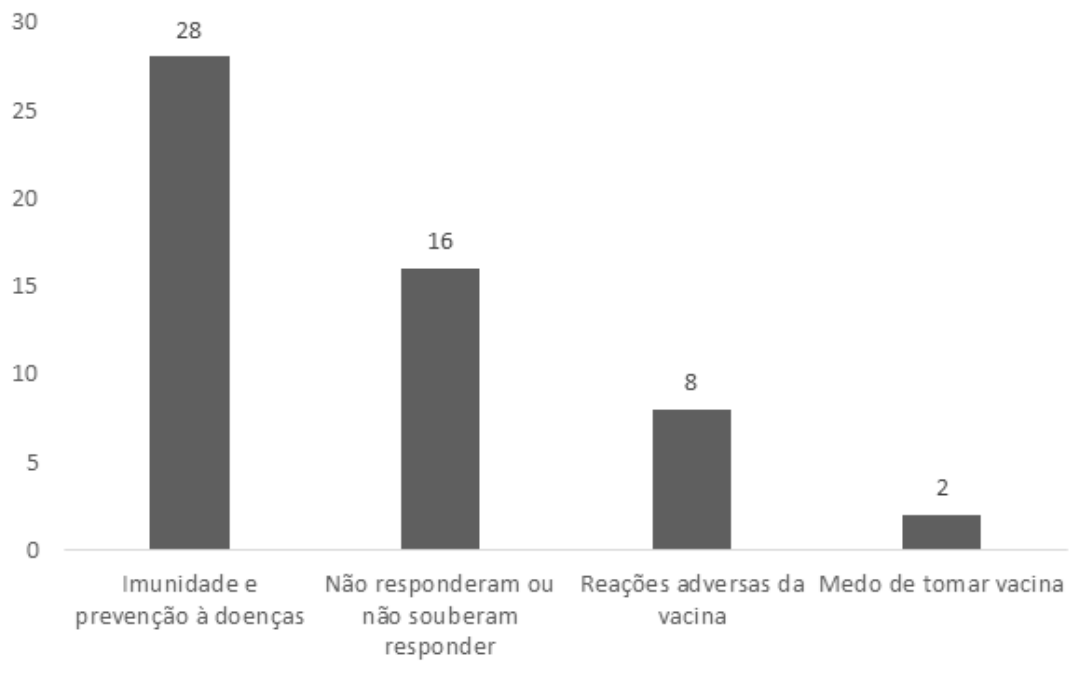

Fonte: autoria própria

A imunidade e a prevenção de doenças foi o conjunto de ideias mais presente nas respostas (28 estudantes), demonstrando compreensão adequada da mensagem imagem usada. Também nesta questão, houve um elevado número de alunos (16) que não respondeu ou não soube responder. Provavelmente há, também neste caso, desinteresse associado à falta de incentivo para a interpretação de imagens. Ferreira e 
Ensino, Saúde e Ambiente - V9 (2), pp. 12-26, Ago. 2016.

Queiroz (2012) destacam a importância de se trabalhar não só o conteúdo propriamente dito, mas também que haja um incentivo à leitura e à pesquisa.

Buscando auxiliar no entendimento das questões envolvidas no ensino, na tentativa de melhorar a aprendizagem de microbiologia, foi planejada e executada uma apresentação na qual os autores deste trabalho abordaram conteúdos da microbiologia geral, com ênfase nos benefícios que os microrganismos podem trazer ao ser humano, evolvendo aplicações em biotecnologia, agricultura, microbiota natural, decomposição e produção primária.

Em função da limitação dos espaços da escola e da quantidade de equipamentos, ficou impossibilitado o uso do projetor multimídia e a apresentação foi feita no quadro por meio de esquemas ilustrativos. Inicialmente houve certa resistência dos alunos quanto à interação no momento da aula/apresentação, principalmente quando eles eram questionados ou estimulados a falar. Entretanto, com as propostas de contextualização iniciais, eles foram demonstrando interesse por já conhecerem alguns conceitos da área de conhecimento, o que favoreceu o desencadeamento do diálogo e consequentemente de uma situação de aprendizagem para as relações propostas.

Um dos assuntos mais comentados na ocasião foi a produção de alimentos e bebidas por meio da fermentação biológica, pois os estudantes afirmaram não relacionar anteriormente o termo ao envolvimento de microrganismos nos processos. Como diagnosticado pela análise dos questionários aplicados sobre aprendizagem em microbiologia no Ensino Médio, eles demonstraram ter pouca ou nenhuma informação sobre o assunto, exceto sobre a ligação entre micróbios e doenças.

Alguns alunos afirmaram nunca ter ouvido falar sobre a existência de alimentos produzidos a partir da ação microbiana. Outros demonstraram ter alguma noção de que estes seres são importantes para a natureza, embora não tenham completado a ideia de que essas importâncias refletem de maneira positiva, direta ou indiretamente, na vida do ser humano.

\section{CONSIDERAÇÕES FINAIS}


Ensino, Saúde e Ambiente - V9 (2), pp. 12-26, Ago. 2016.

De modo geral os resultados obtidos apresentaram algumas contradições. Os mesmos alunos que nas questões objetivas demonstraram, em sua maioria, ter consciência da presença da microbiologia no seu cotidiano, não conseguiram formular respostas que reforçassem esse entendimento. Um dos motivos para que haja a contradição observada é que, mesmo sendo um assunto amplamente associado ao noticiário diário da mídia, assim como à biotecnologia, a microbiologia vem sendo trabalhada na sala de aula de forma fragmentada e descontextualizada.

Com esse trabalho foi possível reforçar a ideia de que o ensino, particularmente de biologia, precisa ser cada vez mais aplicado e contextualizado, independentemente da modalidade didática escolhida para cada situação. O que se pretende é que haja participação e interação dos estudantes nas situações didáticas administradas pelo professor para que a aprendizagem seja um processo construtivo.

O professor do Ensino Básico pode e deve ser também um professopesquisador que busca entender seus alunos e avaliar as suas próprias ações. Como discutem Vilani, Freitas e Brasilis (2009), é importante que o professor faça uma reflexão sistemática da sua atividade docente. Esta função tende a melhorar a compreensão de suas atitudes e práticas, como também o entendimento de que o aluno é o responsável pela própria aprendizagem, orientado e estimulado pelo professor.

A pesquisa-ação, portanto, deve passar a ser integrante no planejamento dos professores para que estes possam interferir melhor na conduta do processo de ensinoaprendizagem. No presente trabalho a pesquisa-ação foi um instrumento que permitiu analisar e reforçar a necessidade dos discentes, quanto à interação nas aulas, buscandose o desenvolvimento da capacidade crítica e interpretativa, e a necessidade dos docentes, quanto à função de motivar e associar os temas trabalhados ao cotidiano dos estudantes.

\section{REFERÊNCIAS}

ANTUNES, C. H.; PILEGGI, M.; PAZDA, A. K. Por que a visão científica da microbiologia não tem o mesmo foco na percepção da microbiologia no ensino médio? In: SIMPÓSIO NACIONAL DE ENSINO DE CIÊNCIA E TECNOLOGIA, 3. Ponta Grossa, 2012. 
Ensino, Saúde e Ambiente - V9 (2), pp. 12-26, Ago. 2016.

AZEVEDO, T. M.; SODRÉ-NETO, L. Conhecimento de estudantes da educação básica sobre bactérias: Saber científico e concepções alternativas. Revista de Educação,

Ciência e Matemática, v. 4 n.2 p. 22-36, 2014.

BARBOSA, F. H. F.; BARBOSA, L. P. J. L. Alternativas metodológicas em Microbiologia-viabilizando atividades práticas. Revista de Biologia e Ciências da Terra, v. 10, n. 2, p. 134-143, 2010.

BRASIL. Senado Federal. Lei de Diretrizes e Bases da Educação Nacional: ${ }^{\circ}$ 9394/96. Brasília: 1996.

CÂNDIDO, M. S. C.; SANTOS, M. G.; AZEVEDO, T. M.; SODRÉ-NETO, L. Microbiologia no ensino médio: analisando a realidade e sugerindo alternativas de ensino numa escola estadual paraibana. Ensino, Saúde e Ambiente, v. 8, n. 1, 2015.

ENGEL, G. I. Pesquisa-ação. Educar em Revista, n. 16, p. 181-191, 2000.

ESCODINO D. A.; GÓES A. C. S. Alfabetização científica e aprendizagem significativa: Situação de alunos de escolas estaduais do Rio de Janeiro com relação a conceitos de Biologia molecular. Investigações em Ensino de Ciências - v.18, n. 3, p. 563-579, 2013

FERREIRA, L. N. A.; QUEIROZ, S. L.. Textos de divulgação científica no ensino de ciências: uma revisão. Alexandria: Revista de Educação em Ciência e Tecnologia, v. 5, n. 1, p. 3-31, 2012.

JACOBUCCI, D. F. C.; JACOBUCCI, G. B. Abrindo o Tubo de Ensaio: o que sabemos sobre as pesquisas em Divulgação Científica e Ensino de Microbiologia no

Brasil?. JCOM, v. 8, p. 2, 2009.

KRUMMENAUER W. L.; CABRAL DA COSTA S. S. Mapas conceituais como instrumentos de avaliação na educação de jovens e adultos. Experiências em Ensino de Ciências - v.4, n.2, p. 33-38, 2009.

OVIGLI D. F. B. Microrganismos? Sim, na saúde e na doença! Diminuindo distâncias entre universidade e escola pública. Experiências em Ensino de Ciências - v.5, n.1, p.145-158, 2010.

SILVA, M. S.; BASTOS, S. N. Ensino de microbiologia: percepção de docentes e discentes nas escolas públicas de mosqueiro, Belém, Pará. In: III Terceiro encontro Nacional de ensino de ciências e da saúde e do ambiente, Niterói/ RJ, 2012.

SPELTA, L. M. P. B.; NUNES, F. P. B.; DA SILVA, J. R. S.; URSI, S.; PRESTES, M. E. A pesquisa-ação na prática docente na disciplina Introdução ao Ensino de Biologia do Curso de Ciências Biológicas do Instituto de Biociências da Universidade de São Paulo. Revista Brasileira de Pesquisa em Educação em Ciências, v. 12, n. 2, p. 7192, 2012. 
Ensino, Saúde e Ambiente - V9 (2), pp. 12-26, Ago. 2016.

THIOLLENT, M. J. M.; COLETTE, M. M. Pesquisa-ação, formação de professores e diversidade. Acta Scientiarum. Human and Social Sciences, v. 36, n. 2, p. 207-216, 2014.

TRIPP, D. Pesquisa-ação: uma introdução metodológica. Educação e pesquisa, v. 31, n. 3, p. 443-466, 2005.

VILLANI, A.; FREITAS, D. ; BRASILIS, R. Professor Pesquisador: o caso Rosa.

Ciência \& Educação, v. 15, n. 3, p. 479-496, 2009. 